Document downloaded from:

http://hdl.handle.net/10251/108466

This paper must be cited as:

Uscátegui, YL.; Arevalo-Alquichire, SJ.; Gómez-Tejedor, J.; Vallés Lluch, A.; Diaz, LE.; Valero, MF. (2017). Polyurethane-based bioadhesive synthesized from polyols derived from castor oil (Ricinus communis) and low concentration of chitosan. Journal of Materials Research. 32(19):3699-3711. doi:10.1557/jmr.2017.371

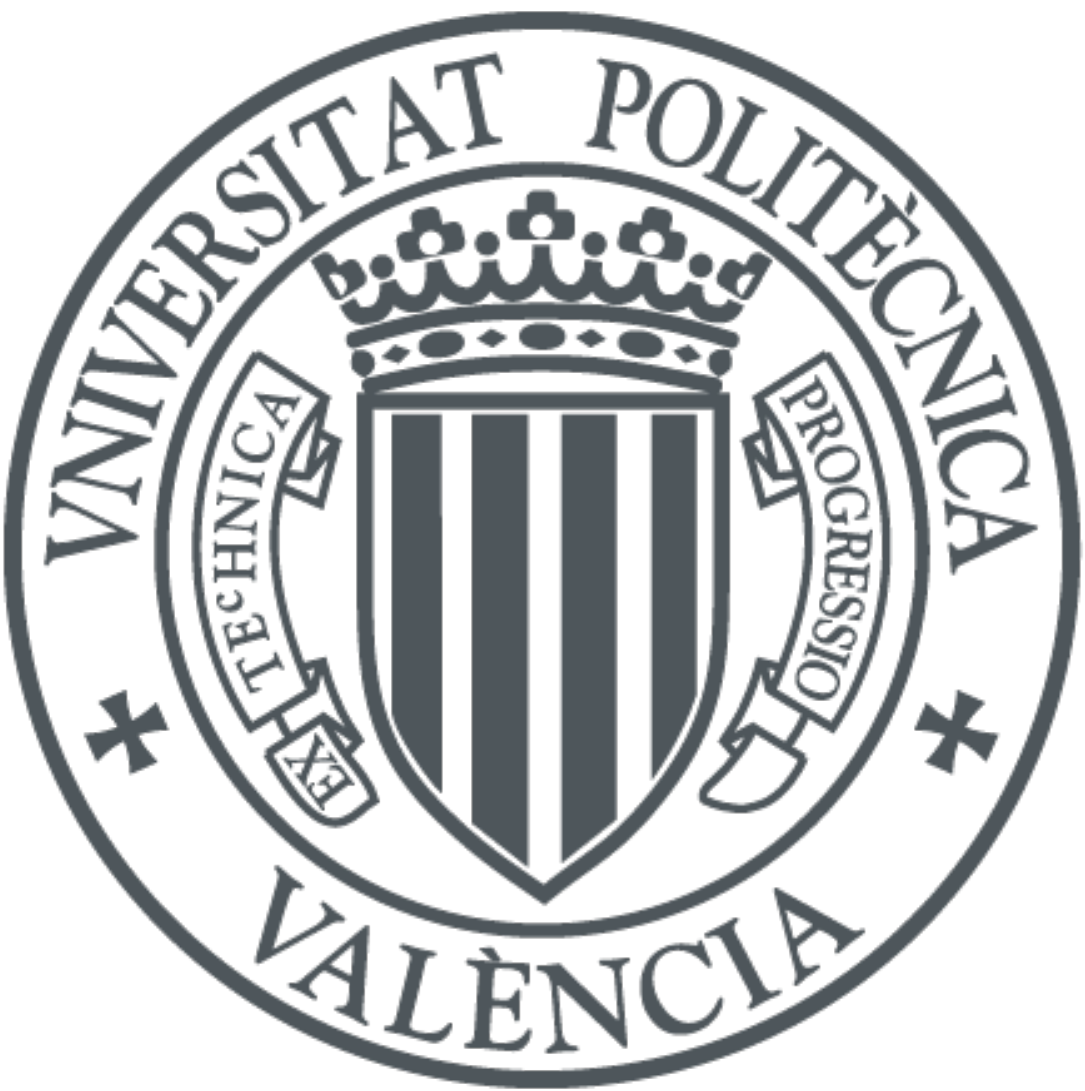

The final publication is available at

https://doi.org/10.1557/jmr.2017.371

Copyright Cambridge University Press (Materials Research Society)

Additional Information 
Journal of material research, 2017, 32 (19): 3699-3711, doi:10.1557/jmr.2017.371

\title{
Polyurethane-based bioadhesive synthesized from polyols derived from castor oil (Ricinus communis) and low concentration of chitosan
}

\author{
Journal of material research, Volume 32, Issue 19, pp. 3699-3711 \\ doi:10.1557/jmr.2017.371
}

Yomaira L. Uscátegui ${ }^{1}$, Said J. Arévalo-Alquichire ${ }^{1}$, José A. Gómez-Tejedor ${ }^{2,3}$, Ana VallésLluch $^{2}$, Luis E. Díaz ${ }^{4}$, Manuel F. Valero ${ }^{1 *}$

${ }^{1}$ Doctoral Program in Biosciences, Research Group on Energy, Materials and Environment, Universidad de La Sabana, Campus Universitario del Puente del Común, Autopista Norte de Bogotá, D.C. Call Center: (+57)1-8616666. Fax: (+57)1-8615555. Apartado: 140013. Chía, Cundinamarca, Colombia

${ }^{2}$ Center for Biomaterials and Tissue Engineering, Universitat Politècnica de València, Camino de Vera, s/n, 46022. Fax (+34) 963879009. Valencia, Spain

${ }^{3}$ Biomedical Research Networking Center in Bioengineering, Biomaterials, and Nanomedicine (CIBER-BBN), Spain

${ }^{4}$ Bioprospecting Research Group, Universidad de La Sabana, Campus Universitario del Puente del Común, Autopista Norte de Bogotá, D.C. Call Center: (+57)1-8616666. Fax: (+57)18615555. Apartado: 140013. Chía, Cundinamarca, Colombia

* Corresponding author: Telephone number: (+57)1-861 5555 ext. 25218

e-mail address: manuel.valero@unisabana.edu.co 
Journal of material research, 2017, 32 (19): 3699-3711, doi:10.1557/jmr.2017.371

\begin{abstract}
Polyurethane-based bioadhesive was synthesized with polyols derived from castor oil (chemically modified and unmodified) and hexamethylene diisocyanate with chitosan addition as bioactive filler. The objective was to evaluate the effect of type of polyols with the incorporation of low-concentrations of chitosan on the mechanical and biological properties of the polymer to obtain suitable materials in the design of biomaterials. The results showed that increasing physical crosslinking increased the mechanical and adhesive properties. An in vitro cytotoxic test of polyurethanes showed cellular viability. The biocompatibility of the polyurethanes favours the adhesion of L929 cells at 6, 24 and 48 hours. The polyurethanes showed bacterial inhibition depending on the polyol and percentage of chitosan. The antibacterial effect of the polyurethanes for Escherichia coli decreased $60 \%$ to $90 \%$ after 24 hours. The mechanical and adhesive properties together with biological response in this research suggested these polyurethanes as external application tissue bioadhesives.
\end{abstract}

Keywords: adhesion, biomedical devices, chemical reaction.

\title{
I. INTRODUCTION
}

Recent advances in synthetic polymers in the biomedical field have increased the need for designing materials with high biocompatibility, easy processing, and antibacterial properties, avoiding additional processing steps related to the modification of the polymer surface. One biomedical application of synthetic polymers is bioadhesives. In the last five years, surgical tissue adhesives have undergone significant advances. ${ }^{1,2}$ Bioadhesive is understood as the 
Journal of material research, 2017, 32 (19): 3699-3711, doi:10.1557/jmr.2017.371

adhesion of a polymer (natural or synthetic) with biological tissues such as skin or mucous membranes. Adhesion is the attachment between the surfaces of two substances that can be similar or dissimilar in structure. The process of adhesion can occur from energy obtained from chemical or physical linkages of chemical structures. ${ }^{3}$ Bioadhesives are used in drug delivery, implantation of biomedical devices, tissue engineering, dental and bone applications, and as an alternative internal and external wound closures in which healing and infection prevention are encouraged. ${ }^{4-7}$ The use of bioadhesives has been enhanced by the search for non-invasive biomedical devices for surgical practice, which help control blood loss and promote tissue healing. ${ }^{8}$ Biomedical adhesives must have strong binding strength, ease of application, tissue biocompatibility, biodegradable by products, minimal tissue reactivity, and reasonable cost. ${ }^{1}$

The most common bioadhesives are fibrin, cyanoacrylates, and an albumin-glutaraldehyde blend, which are characterized by rapid curing times, biodegradability and biocompatibility. $6,7,9$ These bioadhesive materials exhibit disadvantages such as poor adhesion to tissues, rapid degradation, inflammation problems and allergic reactions. ${ }^{6,9}$ Traditional bioadhesives do not have antibacterial properties, so it is necessary to add compounds that fulfill this function, increasing costs. ${ }^{10}$ There are reasons to study polymeric materials to mitigate these drawbacks. In addition, polymer-based adhesives have physical, mechanical and chemical properties that promote adhesion. ${ }^{3}$

One of these polymers corresponds to the polyurethanes (PUs). PUs are a class of synthetic polymers that are used as biomaterials. PUs have advantages such as flexibility, elasticity, durability, ease of processing and biocompatibility. ${ }^{11}$ These properties are generated by the block structure that contains hard and flexible segments joined together by urethane groups. ${ }^{12,13}$ The mechanical, thermal, chemical and biological properties of PUs can be modified in synthesis, ${ }^{13}$ 
Journal of material research, 2017, 32 (19): 3699-3711, doi:10.1557/jmr.2017.371

as the type of polyol or the polymers addition, such as chitosan (Ch) modifies the properties such as the biocompatibility. ${ }^{14} \mathrm{Ch}$ is a polysaccharide that is obtained from renewable sources, as it is part of the structure of some crustaceans. Ch is characterized by being biocompatible, biodegradable, bioadhesive, and non-toxic and has antimicrobial properties. ${ }^{14-17}$ These properties facilitate the use of this material in the design of biomaterials. Some natural polysaccharides, such as Ch, are characterized by forming covalent bonds with biological tissues via bio-adhesion due to hydroxyl, carboxyl or amino groups in the structure. ${ }^{15}$

The selection of the polyol in synthesis allows for modification of the properties of PUs. Polyols derived from vegetable oil are currently used in PUs synthesis. Vegetable oils have different chemical structures and reactive sites that allow for generation of different modified polyols. In addition, polyols derived from vegetable oils can replace the use of polyols derived from fossil sources. ${ }^{18,19}$ One oil used in the synthesis of PUs is castor oil. Castor oil is characterized by hydroxyl groups in the chain that react with isocyanates generating different morphological and mechanical properties. ${ }^{20,21}$ PUs derived from castor oil may exhibit antibacterial activity and applications of these polymers for wound closure have been reported. ${ }^{11}$ According to the previously information there are works related to biodhesive design. But in the best of our knowledge, there are not works about polyurethane based bioadhesive from castor oil polyols and chitosan describing the effect of composition on biological properties such as cell viability, cell adhesion and antimicrobial activity. PUs with these properties avoid subsequent processes of adaptation as biomedical devices. Therefore, the objective of this work was to synthesize PU-based bioadhesives for external applications using polyols derived from castor oil (Ricinus communis) and hexamethylene diisocyanate (HDI) with the Ch addition. We evaluated the effect of the chemical modification of polyols derived from castor oil and the Ch addition on 
Journal of material research, 2017, 32 (19): 3699-3711, doi:10.1557/jmr.2017.371

the mechanical, morphological and biological properties of polymeric matrices that may be useful in biomedical applications such as bioadhesives.

\section{EXPERIMENTAL}

\section{A. Materials}

Castor oil was obtained from Químicos Campota y Cía, Ltda., Colombia. Low-molecularweight chitosan (Ch) with 75-85 \% deacetylated and hexamethylene diisocyanate (HDI) were obtained from Sigma-Aldrich Chemical Co., St. Louis, MO, USA. Phosphate buffered saline (PBS) was prepared by dissolving $\mathrm{KH}_{2} \mathrm{PO}_{4}$ and $\mathrm{NaHPO}_{4} 0.01 \mathrm{M}$ in $0.8 \% \mathrm{NaCl}$ at $\mathrm{pH} 7.4$ and pentaerythritol were obtained from Merck \& Co., Inc. Germany. MTT (3-[4,5-dimethylthiazol-2yl] -2,5-diphenyl-2H-tetrazolium bromide), trypsin 2.5\% (10X), penicillin-streptomycin (10,000 $\mu \mathrm{g}$ of penicillin and 10,000 $\mu \mathrm{g}$ streptomycin per milliliter) for cell culture, and RPMI 1640 (Roswell Park Memorial Institute) were obtained from Gibco/Invitrogen, Paisley, UK. Fetal bovine serum (FBS) was obtained from Eurobio, Les Ulis, France. Trypticase soy broth (TSB) and trypticase soy agar (TSA) were obtained from Scharlau Co, Spain. Embryonic mouse fibroblasts L-929 (ATCC® CCL-1) and Escherichia coli (ATCC® 2469) were obtained from the strain library of the Universidad de La Sabana.

\section{B. Synthesis of PUs}

1. Transesterification of castor oil using pentaerythritol

In PU synthesis, 3 polyols derived from castor oil (CO, P0 and P1) were used. CO is to unmodified castor oil, and P0 and P1 were obtained by chemical modification of CO by transesterification with pentaerythritol (1.32\% and 2.64 mol\% of pentaerythritol per mole of 
Journal of material research, 2017, 32 (19): 3699-3711, doi:10.1557/jmr.2017.371

castor oil, respectively ${ }^{22}$. The transesterification reaction was performed in a 3-neck reactor with stirring (300 rpm) and temperature control. In the first stage, the castor oil was dehydrated at 120 ${ }^{\circ} \mathrm{C}$ by $10 \mathrm{~min}$. Then, pentaerythritol was added, and $0.05 \%$ lead oxide was used as catalysts at $210{ }^{\circ} \mathrm{C}$ for $2 \mathrm{~h} .{ }^{23}$ The polyol was allowed to decant for $24 \mathrm{~h}$ and a filtration process was performed to remove catalyst. The hydroxyl number of the polyols was determined using the standard ASTM D1957-86 method.

2. Synthesis of PUs of polyols derived from castor oil

PUs were synthesized using the prepolymer method with HDI maintaining a constant NCO/OH ratio (1:1) (see Table I). ${ }^{24}$ The synthesis was performed in 250-mL glass reactors. The HDI was mixed with the polyol (CO, P0 or P1) at $60{ }^{\circ} \mathrm{C}$ and $300 \mathrm{rpm}$ for $10 \mathrm{~min}$. Then, $\mathrm{Ch}(0,1$, 2 and $3 \% \mathrm{w} / \mathrm{w}$ with respect to the mass of the oil polyol) was added as a filler. The prepolymer was subjected to vacuum and poured into a steel mold $(15.0 \mathrm{~cm}$ x $9.0 \mathrm{~cm}$ x $0.3 \mathrm{~cm})$. The curing process took place at $110^{\circ} \mathrm{C}$ for $12 \mathrm{~h}$ in a drying and heating chamber (Tuttlingen, Germany). The reaction scheme for the synthesis of PUs are provided in Figure 1. 
Journal of material research, 2017, 32 (19): 3699-3711, doi:10.1557/jmr.2017.371

TABLE I. Polyurethane compositions.

\begin{tabular}{|c|c|c|}
\hline Polyurethane & Polyol & Chitosan (\% w/w) \\
\hline $\mathrm{CO}-0 \% \mathrm{Ch}$ & Castor oil (CO) & 0 \\
\hline CO-1\%Ch & & 1 \\
\hline $\mathrm{CO}-2 \% \mathrm{Ch}$ & & 2 \\
\hline $\mathrm{CO}-3 \% \mathrm{Ch}$ & & 3 \\
\hline P0-0\%Ch & Polyol 0 (P0; 1.32\% mol of & 0 \\
\hline P0-1\%Ch & pentaerythritol per mol of & 1 \\
\hline P0-2\%Ch & castor oil) & 2 \\
\hline P0-3\%Ch & & 3 \\
\hline P1-0\%Ch & Polyol 1 (P1; 2.64\% mol of & 0 \\
\hline P1-1\%Ch & pentaerythritol per mol of & 1 \\
\hline P1-2\%Ch & castor oil) & 2 \\
\hline P1-3\%Ch & & 3 \\
\hline
\end{tabular}


Journal of material research, 2017, 32 (19): 3699-3711, doi:10.1557/jmr.2017.371

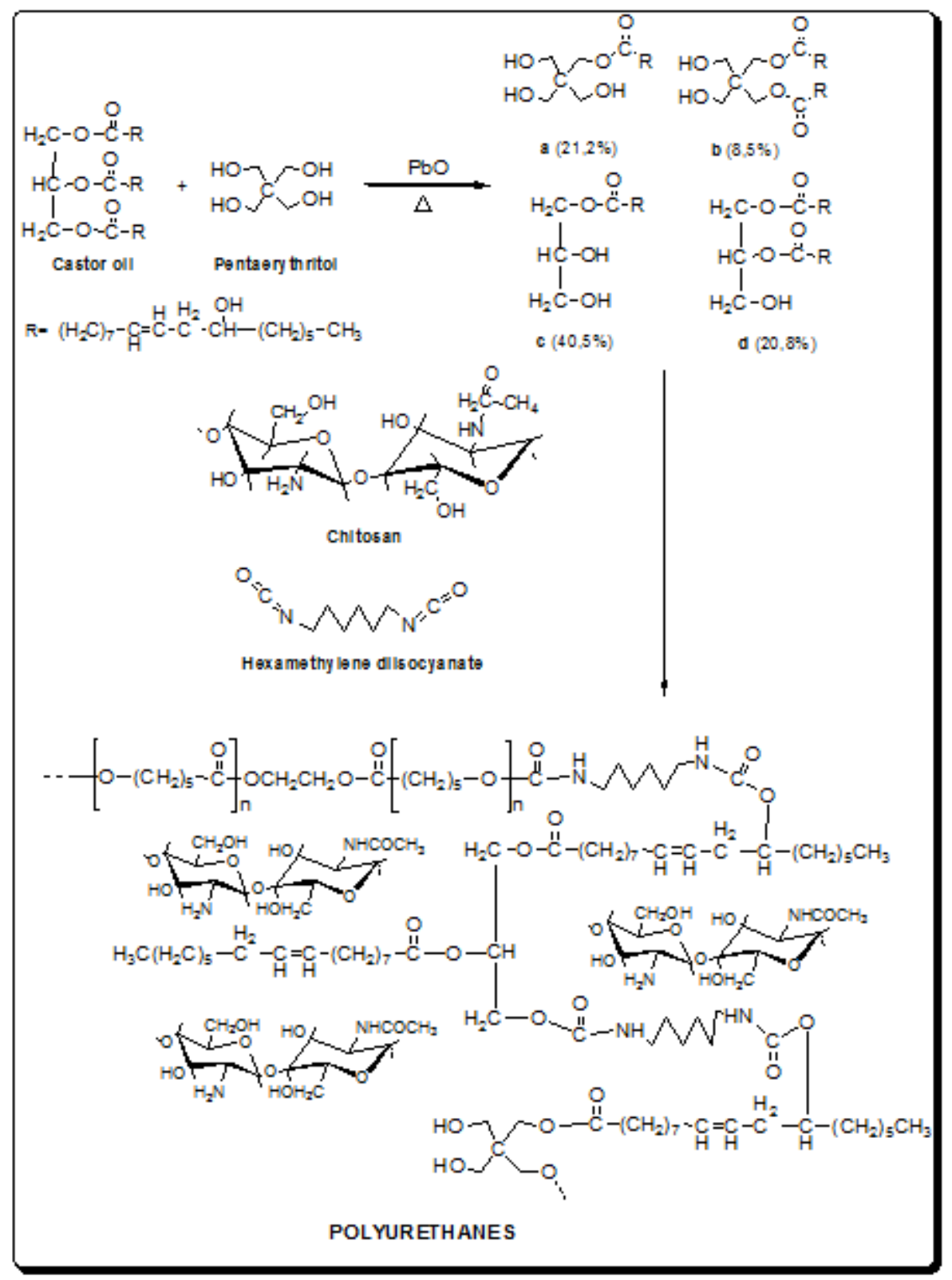

FIG. 1. Reaction scheme for the synthesis or PUs with HDI and Ch. 
Journal of material research, 2017, 32 (19): 3699-3711, doi:10.1557/jmr.2017.371

\section{Characterization of PUs}

1. Mechanical properties

The tensile strength and elongation at break of the PUs were determined following the ASTM D638-10 method. A universal traction machine EZ-LX (Shimadzu, Japan) was used with a 5kN load cell and a jaw displacement speed of $25 \mathrm{~mm} \mathrm{~min}^{-1}$. Three samples of each formulation with dimensions of $40 \mathrm{~mm}$ x $6 \mathrm{~mm}$ x $3 \mathrm{~mm}$ (length $\mathrm{x}$ width $\mathrm{x}$ thickness) were tested. The dynamic hardness test was performed using a shore A durometer (SHR-MARK-III) according to the ASTM D676-59 method. Ten determinations were evaluated for each material. ${ }^{24}$

\section{Adhesive properties}

The adhesive properties were assessed using the scratch resistance according to BS 3900. The impact strength and tensile lap/shear were determined according to ASTM D2794-93 (2010) and ASTM D906-98 (2011), respectively. The adhesion tests were performed on wood substrate in accordance with ASTM D2651-01 (2016) to determine the type of resulting failure. ${ }^{25}$

\section{Thermogravimetric analysis (TGA)}

The thermal behavior of the PUs was evaluated using a thermogravimetric analyzer, model TGA/DCS1 (Mettler Toledo, USA). The heating rate was $25^{\circ} \mathrm{C} \min ^{-1}$ from $25-600{ }^{\circ} \mathrm{C}$ under a nitrogen atmosphere according to ASTM D6370. The weight of the samples was $15 \pm 2 \mathrm{mg}{ }^{26}$ 
Journal of material research, 2017, 32 (19): 3699-3711, doi:10.1557/jmr.2017.371

4. Differential scanning calorimetry analysis (DSC)

The transition temperature of the samples was analyzed using a differential scanning calorimetry analyzer from Perkin-Elmer, model PYRIS 1 DSC. The temperature range was -70 ${ }^{\circ} \mathrm{C}$ to $150{ }^{\circ} \mathrm{C}$ under nitrogen at a flow rate of $20 \mathrm{~mL} \mathrm{~min}{ }^{-1} .{ }^{27}$

5. Water absorption and contact angle

The water absorption percentage and contact angle of the polymeric materials evaluate the hydrophilic behaviors of the PUs. The water absorption percentage was determined by immersing the PU in PBS at $37^{\circ} \mathrm{C}$ until reaching a constant weight. ${ }^{28}$ All assays were performed in triplicate. Eq. (1) calculated the percentage of absorption, where $\mathrm{m}_{0}$ is the initial mass of the PU and $m_{w}$ corresponds to the mass of the sample after obtaining a constant weight. The contact angle was determined using the sessile drop method in a Drop Shape Analysis System DSA (GH11, Krüss, Germany) with distilled water at $20^{\circ} \mathrm{C}$ according to ASTM-D7334-08 (2013). The average contact angle corresponds to ten measurements for each polymeric material. ${ }^{29}$

$$
\% \text { water absorbed }=\frac{\left(m_{0}-m_{w}\right)}{m_{w}} * 100
$$

\section{Scanning electron microscopy (SEM)}

The morphology of the polymeric materials was determined by scanning electron microscopy (SEM) using a JEOL JSM6300 (Japan) microscope operated at a voltage acceleration of $10 \mathrm{kV}$, magnification of 500x and working distance of $15 \mathrm{~mm}$. All samples were gold-plated prior to observation. ${ }^{30}$ 
Journal of material research, 2017, 32 (19): 3699-3711, doi:10.1557/jmr.2017.371

\section{In vitro cytotoxicity of PUs}

1. Cell culture

L-929 mouse embryonic fibroblasts were cultured in RPMI 1640 medium supplemented with fetal bovine serum (10\%) and penicillin-streptomycin (1\%) under $5 \% \mathrm{CO}_{2}$ at $37{ }^{\circ} \mathrm{C}$ until $100 \%$ confluence. ${ }^{31}$ Trypsin EDTA was added to the cells for 3 min at $37^{\circ} \mathrm{C}$ prior to centrifugation at 2000 rpm for 10 min and culturing in fresh RPMI 1640 medium. $^{32}$

\section{In vitro cytotoxicity of PUs}

The cellular viability of the PUs was evaluated using the MTT method defined by ISO/CD 10993-5. ${ }^{33}$ Cylindrical samples with a 3mm diameter and 2mm thickness were sterilized with UV light (260 nm) for 30 min on each side. ${ }^{34}$ Samples of PUs were plated on pre-cultured cells (4.0E+04 cells per well) in 96-well plates with RPMI 1640 medium at $37^{\circ} \mathrm{C}$ with $5 \% \mathrm{CO} 2$ for $24 \mathrm{~h}$. The supernatant was removed, and $100 \mu \mathrm{L}$ of MTT solution (12 mM in PBS) was added for $4 \mathrm{~h}$ at $37^{\circ} \mathrm{C}$. The supernatant was discarded, and $100 \mu \mathrm{L}$ of dimethyldsulfoxide (DMSO) was added for 15 min at $37^{\circ} \mathrm{C}$. Optical density measurement was conducted on an iMark ${ }^{\mathrm{TM}}$ Microplate Reader at a wavelength of $595 \mathrm{~nm}$. All assays were independently performed in triplicate. Cells seeded without polymer and with DMSO were used as control. A commercial polymer (polypropylene) was used as a reference. The cell viability percentage was calculated using Eq. (2): ${ }^{35}$

$$
\text { Cell viability }(\%)=\frac{\left(A b s_{\text {sample }}\right)}{A b s_{\text {control }}} * 100
$$

where $\mathrm{Abs}_{\text {sample }}$ corresponds to the absorbance of cells after contact with PU, and $\mathrm{Abs}_{\text {control }}$ is the absorbance of cells without polymeric material. 
Journal of material research, 2017, 32 (19): 3699-3711, doi:10.1557/jmr.2017.371

\section{E. Cell adhesion testing of PUs}

Cell adhesion assay of the PUs was evaluated using mouse embryonic fibroblasts cell lines of L-929 in RPMI 1640 medium as described in the previous item. Cell adhesion was performed using a methodology described by Pitchaimani et al. ${ }^{36}$ with modifications. Cells were seeded at a density of 4.0E+04 cells per well in 96-well plates, with RPMI 1640 medium on polymers fixed to the bottom of the plate. Samples were incubated at $37^{\circ} \mathrm{C}$ with $5 \% \mathrm{CO} 2$ for different times (6, 24 and 48 h). After the incubation time, non-adhered cells were removed. Cells were washed three times with PBS. $100 \mu \mathrm{L}$ of MTT solution (12 mM in PBS) was added for $4 \mathrm{~h}$ at $37^{\circ} \mathrm{C}$. The supernatant was discarded, and $100 \mu \mathrm{L}$ of DMSO was added for $15 \mathrm{~min}$ at $37^{\circ} \mathrm{C}$. The resulting solution was transferred into the new 96-well plates. Optical density measurement was conducted on an iMark ${ }^{\mathrm{TM}}$ Microplate Reader at a wavelength of $595 \mathrm{~nm}$. All assays were independently performed in triplicate. Cells seeded without polymer were used as control. Cell adhesion was determined with the cell viability percentage (Eq. (2)).

\section{F. Antibacterial testing of PUs}

Antibacterial activity assays of the polymeric materials were performed according to the methodology described by Kara et al. using E. coli (ATCC 2469) bacteria. ${ }^{37}$ The bacterial suspension was grown in TSB at $37^{\circ} \mathrm{C}$ for $16 \mathrm{~h}$ in a Memmert incubator. Aliquots of the bacterial suspension were inoculated in fresh TSB at $37^{\circ} \mathrm{C}$ for $6 \mathrm{~h}$. The bacteria cells were separated by centrifugation of the bacterial suspension at $3000 \mathrm{rpm}$ for $10 \mathrm{~min}$ at $4{ }^{\circ} \mathrm{C}$ in a Sorvall $^{\mathrm{TM}}$ Thermo Scientific Centrifuge. The cells were washed twice with PBS after removing the supernatant. The bacteria were dissolved in PBS at $1.17 \mathrm{E}+07 \mathrm{CFU} \mathrm{mL} \mathrm{m}^{-1}$ of E. coli.

Sterile PUs were placed in microcentrifuge tubes with $100 \mu \mathrm{L}$ of bacterial suspension and 
Journal of material research, 2017, 32 (19): 3699-3711, doi:10.1557/jmr.2017.371

incubated at $37^{\circ} \mathrm{C}$ for $24 \mathrm{~h}$. Then $900 \mu \mathrm{L}$ of sterile PBS was added. The colony forming units (CFU) were determined using serial dilutions seeded in TSA at $37^{\circ} \mathrm{C}$ for $18 \mathrm{~h}$ in a Memmert incubator. A bacterial suspension without polymer was used as a control.

\section{G. Statistical analysis}

The results were analyzed using analysis of variance (ANOVA) and significant differences were determined to be $\mathrm{p}<0.05$. The comparison of means was performed using Student's t-test with SPSS Statistics 23 software. The experiments were conducted using three independent replicates. The results are reported as the mean \pm standard deviation (SD).

\section{RESULTS AND DISCUSSION}

\section{A. Characterization of PUs}

1. Mechanical and adhesive properties

Polymeric matrices synthesized with polyols derived from castor oil (Ricinus communis) and, HDI with the Ch addition were characterized to determine the mechanical and adhesive properties. The results are presented in Table II. 
Journal of material research, 2017, 32 (19): 3699-3711, doi:10.1557/jmr.2017.371

TABLE II. Mechanical and adhesive properties of the PUs.

\begin{tabular}{|c|c|c|c|c|c|c|c|c|}
\hline \multirow[b]{2}{*}{ PU } & \multirow[b]{2}{*}{$\begin{array}{c}\text { Elongati } \\
\text { on at the } \\
\text { break } \\
\text { (\%) }\end{array}$} & \multirow[b]{2}{*}{$\begin{array}{c}\text { Tensile } \\
\text { strength } \\
\text { (MPa) }\end{array}$} & \multirow[b]{2}{*}{$\begin{array}{c}\text { Shore A } \\
\text { hardnes } \\
\text { s }\end{array}$} & \multicolumn{2}{|l|}{ Scratc } & \multicolumn{2}{|c|}{ Tractio } & \multirow[b]{2}{*}{$\begin{array}{c}\text { Type } \\
\text { of } \\
\text { failure }\end{array}$} \\
\hline & & & & $\begin{array}{c}\text { h } \\
\text { resista } \\
\text { nce } \\
\text { (kg) }\end{array}$ & $\begin{array}{c}\text { Impact } \\
\text { resistanc } \\
\text { e (kg } \\
\text { cm) }\end{array}$ & $\begin{array}{l}\text { n and } \\
\text { shear } \\
\text { stress } \\
\text { (MPa) }\end{array}$ & $\begin{array}{l}\text { Adhesi } \\
\text { on } \\
\text { effort } \\
\text { (MPa) }\end{array}$ & \\
\hline CO-0\%Ch & $43.1 \pm 3.4$ & $0.66 \pm 0.1$ & $40.6 \pm 2.2$ & $1.5 \pm 0.1$ & $125 \pm 3.0$ & $6.1 \pm 0.2$ & $4.5 \pm 0.2$ & $\overline{C F}$ \\
\hline CO-1\%Ch & $37.9 \pm 0.0$ & $0.43 \pm 0.1$ & $40.8 \pm 3.1$ & $1.7 \pm 0.1$ & $131 \pm 3.0$ & $6.5 \pm 0.2$ & $4.7 \pm 0.2$ & $\mathrm{CF}$ \\
\hline CO-2\%Ch & $25.2 \pm 0.0$ & $0.17 \pm 0.0$ & $43.0 \pm 1.3$ & $2.0 \pm 0.1$ & $137 \pm 3.0$ & $7.0 \pm 0.2$ & $4.9 \pm 0.2$ & $\mathrm{CF}$ \\
\hline CO-3\%Ch & $33.4 \pm 0.0$ & $0.54 \pm 0.0$ & $40.8 \pm 1.0$ & $2.1 \pm 0.1$ & $142 \pm 3.0$ & $7.1 \pm 0.2$ & $5.0 \pm 0.2$ & $\mathrm{CF}$ \\
\hline P0-0\%Ch & $34.5 \pm 2.1$ & $0.76 \pm 0.1$ & $54.1 \pm 1.0$ & $1.9 \pm 0.1$ & $132 \pm 3.0$ & $6.5 \pm 0.2$ & $4.9 \pm 0.2$ & $\mathrm{CF}$ \\
\hline P0-1\%Ch & $32.8 \pm 1.0$ & $0.64 \pm 0.1$ & $50.4 \pm 0.8$ & $2.3 \pm 0.1$ & $139 \pm 3.0$ & $6.7 \pm 0.2$ & $5.2 \pm 0.2$ & $\mathrm{CF}$ \\
\hline P0-2\%Ch & $31.8 \pm 1.3$ & $0.58 \pm 0.1$ & $50.8 \pm 0.6$ & $2.7 \pm 0.1$ & $146 \pm 3.0$ & $7.2 \pm 0.2$ & $5.6 \pm 0.2$ & $\mathrm{CF}$ \\
\hline P0-3\%Ch & $29.9 \pm 3.1$ & $0.56 \pm 0.1$ & $47.8 \pm 2.4$ & $3.1 \pm 0.1$ & $151 \pm 3.0$ & $7.4 \pm 0.2$ & $5.8 \pm 0.2$ & $\mathrm{CF}$ \\
\hline P1-0\%Ch & $35.9 \pm 0.5$ & $0.90 \pm 0.1$ & $59.7 \pm 0.7$ & $2.2 \pm 0.1$ & $142 \pm 3.0$ & $6.8 \pm 0.2$ & $4.9 \pm 0.2$ & $\mathrm{CF}$ \\
\hline P1-1\%Ch & $34.1 \pm 0.8$ & $0.96 \pm 0.1$ & $60.0 \pm 0.9$ & $2.6 \pm 0.1$ & $152 \pm 3.0$ & $7.1 \pm 0.2$ & $5.2 \pm 0.2$ & $\mathrm{CF}+\mathrm{AF}$ \\
\hline P1-2\%Ch & $24.1 \pm 2.4$ & $0.76 \pm 0.1$ & $59.2 \pm 1.2$ & $3.1 \pm 0.1$ & $160 \pm 3.0$ & $7.4 \pm 0.2$ & $5.6 \pm 0.2$ & $\mathrm{CF}+\mathrm{AF}$ \\
\hline P1-3\%Ch & $33.1 \pm 1.7$ & $0.87 \pm 0.1$ & $59.1 \pm 0.7$ & $3.3 \pm 0.1$ & $163 \pm 3.0$ & $7.6 \pm 0.2$ & $5.8 \pm 0.2$ & $\mathrm{CF}+\mathrm{AF}$ \\
\hline
\end{tabular}

Notes: The results of mechanical and adhesive properties are given as the mean \pm SD $(n=3)$. The Shore A hardness result is given as the mean \pm SD $(n=10)$.

CF: cohesive failure of the adhesive; AF: adhesive failure of the adhesive 
Journal of material research, 2017, 32 (19): 3699-3711, doi:10.1557/jmr.2017.371

The hydroxyl number of each polyol was obtained after chemical modification (160, 191 and $236 \mathrm{mg} \mathrm{KOH} \mathrm{g-1} \mathrm{sample} \mathrm{for} \mathrm{CO,} \mathrm{P0} \mathrm{and} \mathrm{P1,} \mathrm{respectively).} \mathrm{The} \mathrm{analysis} \mathrm{of} \mathrm{the} \mathrm{elongation} \mathrm{at}$ break presented statistical differences $(\mathrm{p}<0.05)$ between the polyol $\mathrm{CO}$ and the other polyols (P0 and P1). The percentages of elongation at break decrease with the chemical modification of the polyols. In polymers from the polyol CO, it was observed that increasing in the concentration of Ch tends to decrease the percentage of elongation. There were no differences related to the effect of the Ch addition into matrices of P0 polyol. In P1 polyol-based PUs, the concentration of 2\% Ch presented a statistically significant difference with a smaller percentage of elongation.

The tensile strength properties were studied using statistical analysis showed that there were significant differences $(\mathrm{p}<0.05)$ between the type of polyols used in synthesis. The chemical modification performed on the polyols increases the maximum stress due to an increase in the physical crosslinks of the polymers. The effects of Ch addition on the tensile force were determined. Statistically, they do not present differences so it can be inferred that the Ch addition do not influence the maximum tension and thus, the factor that influences the tensile force depends on the type of polyol used in synthesis.

The tensile strength results from a previous study with polymer matrices synthesized using the same polyols (CO, P0 and P1) with isophorone diisocyanate ${ }^{20}$ show lower values when HDI is used instead of diisocyanate. This may be due to the chemical structure of the HDI because it is a linear aliphatic diisocyanate, whereas and the isophorone diisocyanate has a cyclic structure that allows for higher tensile strength than materials from linear diisocyanates.

Anirudhan et al. ${ }^{16}$ designed a transdermal bioadhesive based on chitosan and hyaluronic acid for controlled release of lidocaine. The authors determined that the tensile force was approximately $0.5 \mathrm{MPa}$. 
Journal of material research, 2017, 32 (19): 3699-3711, doi:10.1557/jmr.2017.371

As part of the mechanical property evaluation, the dynamic hardness test of materials was conducted and the results are presented in Table II. According to the statistical analysis, there were significant differences $(\mathrm{p}<0.05)$ between the polyols used. It can be seen that increasing the functionality of the polyol increases the material response, so PUs derived from P1 presented higher hardness than P0 and CO. The polyols derived from the transesterification with pentaerythritol produce materials with higher crosslink density which is related to better mechanical performance. These values are similar to those described by Valero et al. ${ }^{38}$, who studied the mechanical performance of PUs with polyols derived from castor oil obtained by transesterification with pentaerythritol and diphenyl methane diisocyanate (MDI) at $\mathrm{NCO} / \mathrm{OH}=$ 0,7 . The difference between the ratios and the hardness response is caused by the lower reactivity of HDI with respect to MDI, MDI is an aromatic diisocyanate used in industry that is characterized by high reactivity. ${ }^{12}$ The decrease in the hard segments of the PUs obtained by the reaction of the -OH groups of the polyol and NCO of the HDI causes a reduction in the mechanical performance.

For the adhesion properties, the scratch resistance of the PUs was determined and the results are shown in Table II. The statistical analysis showed significant differences for each polyol used. An increase in resistance was observed as the physical PU cross-linkage increased. This was achieved by the chemical modification of the polyols used in synthesis. These results agree with those reported by Cakić et al. ${ }^{39}$, who synthesized PU-based adhesives from polyols derived from castor oil with residues of polyethylene terephthalate. The authors attributed the increase in hardness to the cross-link density achieved by modifying the polyols by glycosylation of the castor oil, which generated an increase in the stiffness of the main chain. ${ }^{39}$ 
Journal of material research, 2017, 32 (19): 3699-3711, doi:10.1557/jmr.2017.371

Kathalewar et al. ${ }^{40}$ synthesized isocyanate-free PUs to obtain eco-friendly materials for applications in coatings. The authors evaluated the scratch resistance, and the results ranged from 0.9 to $2.8 \mathrm{~kg}$. The authors affirm that the results are due to the crosslinked structure of the PUs. Similar results were found in this research, where the maximum was $3.3 \mathrm{~kg}$ for polyol P1 which has a higher crosslink density. ${ }^{40}$

The impact strength, tensile lap/shear and adhesion effort exhibit the same behavior. The results show that increasing the functionality of the polyol increases the material response, as PUs derived from P1 presented higher hardness results than to P0 and CO. It can also be inferred that increasing the amount of $\mathrm{Ch}$ increased the adhesive properties (Table II). The Ch can be used as a biomedical adhesive such as in drug delivery or tissue engineering due to its high cohesive strength. These adhesive properties depend on the -OH, $-\mathrm{NH}_{3}{ }^{+}$, and -NHCOCH3 groups of the chemical structure. The groups can generate non-covalent, inter- and intra-chain interactions that improved adhesion. ${ }^{3}$

Another important property of PU-type bioadhesives is the type of failure. Evaluation of the type of failure showed a cohesive failure of the PUs synthetized with CO and P0. These polymers present a failure in the adhesive material itself. Conversely, the type of failure exhibited by PUs derived from P1 is a combination of cohesive and adhesive failure which means that those polymers exhibit an intermolecular failure between the adhesive and the substrate with cross-linked structures. ${ }^{41}$ 
Journal of material research, 2017, 32 (19): 3699-3711, doi:10.1557/jmr.2017.371

2. Thermogravimetric analysis (TGA)

A thermogravimetric analysis was performed using thermograms of the PUs. The results for six matrices corresponding to the polymer matrices without $\mathrm{Ch}$ and to those containing the highest percentage of Ch according to the type of polyol employed are presented in Figure 2 (a).

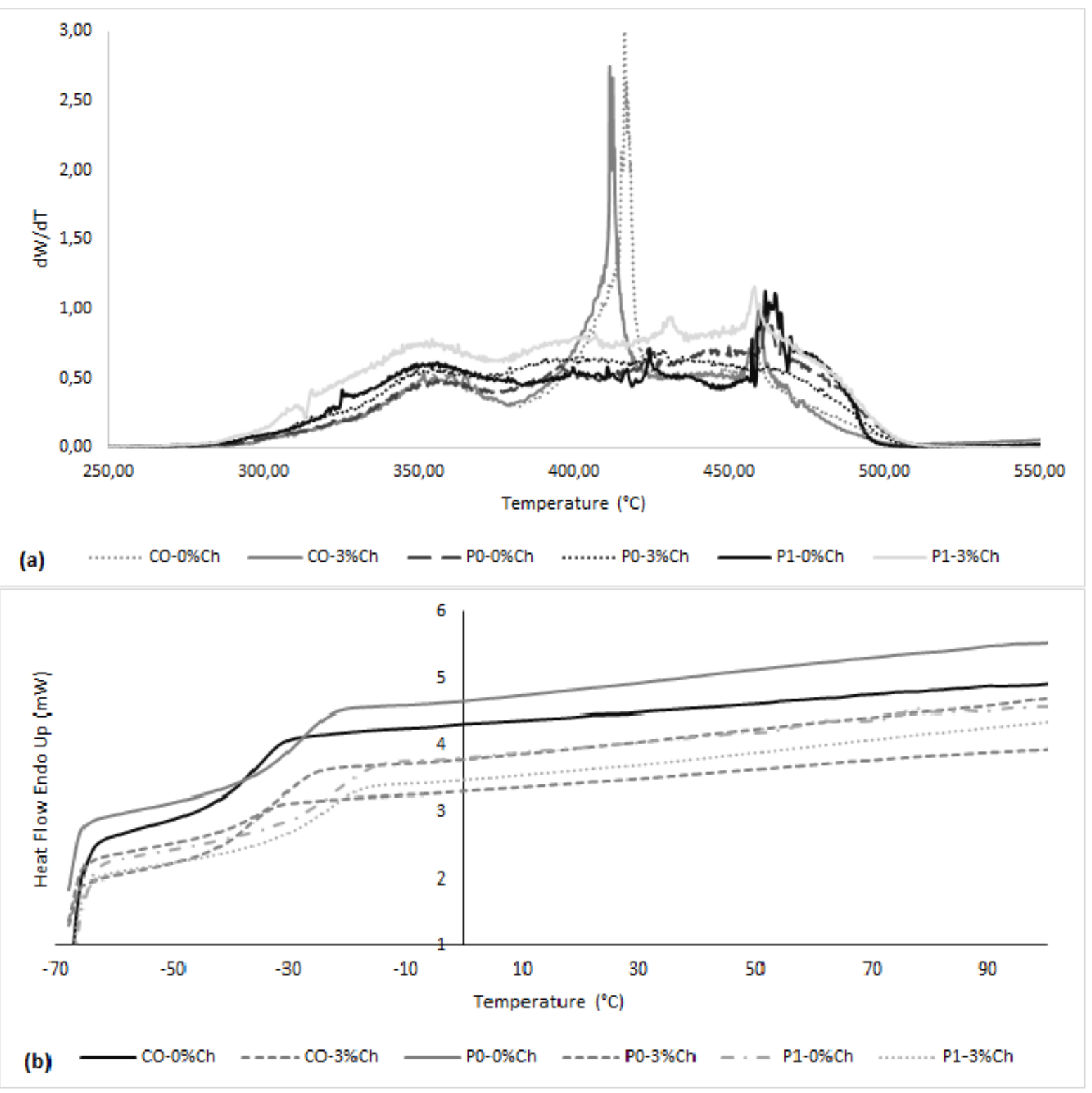

FIG. 2. (a) Derivative of the weight versus temperature of the PU thermograms. (b) DSC curves of the PUs. 
Journal of material research, 2017, 32 (19): 3699-3711, doi:10.1557/jmr.2017.371

For PUs synthesized with polyols with $0 \%$ and $3 \%$ of $\mathrm{Ch}$, the thermal behavior maintains the trend, indicating that there are no displacements of the degradation temperatures when modified polyols and Ch are used. In the derived curves from the thermogravimetric analysis, several peaks were observed, which agrees with other authors who affirm that the mechanism of PU degradation is complex due to the formation of diverse compounds in the process. ${ }^{26}$

A thermogram was obtained for each polymer, allowing for determination of the stability of the PUs synthesized in this study (complete results are not shown). The thermograms show that all PUs are stable at temperatures below $300{ }^{\circ} \mathrm{C}$ and exhibit complete degradation at temperatures close to $600{ }^{\circ} \mathrm{C}$. These degradation temperatures coincide with those reported for a PU synthesized with castor oil and isophorone diisocyanate that was proposed as a surgical adhesive. In addition, the degradation temperatures do not affect the biomedical application because the physiological temperature is far lower $\left(\approx 37^{\circ} \mathrm{C}\right) .{ }^{42}$

Three degradation stages of the PUs were determined using TGA thermograms. The first stage was between approximately $350-370{ }^{\circ} \mathrm{C}$. This stage corresponds to the thermal degradation of the urethane bonds that are formed in the hard segments and are characterized by being thermally unstable. ${ }^{43}$ The second stage was approximately $390-430{ }^{\circ} \mathrm{C}$, corresponding to the degradation of the soft segments. This is in agreement with Aung et al. ${ }^{41}$, who synthesized Jatropha oil-based-polyurethane adhesives and determined that the hard segments decompose before the soft segments (close to $400{ }^{\circ} \mathrm{C}$ ). The last stage between $430-500{ }^{\circ} \mathrm{C}$ corresponds to the thermal degradation of the remaining fatty acid double bonds of the castor oil. ${ }^{44}$

This is in agreement with a study of polymers synthesized with castor oil (CO) and isophorone diisocyanate with polycaprolactone and $\mathrm{Ch}$ at different concentrations in which the $\mathrm{T}_{\max } 1$ was between $250-370{ }^{\circ} \mathrm{C}, \mathrm{T}_{\max } 2$ was $375-430{ }^{\circ} \mathrm{C}$ and $\mathrm{T}^{\max } 3$ was $425-430{ }^{\circ} \mathrm{C},{ }^{24}$ indicating 
Journal of material research, 2017, 32 (19): 3699-3711, doi:10.1557/jmr.2017.371

that the thermal stability of modified castor oil-polyol-based PUs was not affected by the type of diisocyanate and additives such as Ch used in synthesis.

In relation to the thermal behavior of chitosan, an isothermal $\left(110^{\circ} \mathrm{C}\right.$ for $\left.12 \mathrm{~h}\right)$ and dynamic analysis $\left(25-600{ }^{\circ} \mathrm{C}\right)$ was performed (data not shown). With the isothermal analysis, no significant variation of the chitosan was observed indicating that the structure of the chitosan is not affected during the curing process of the polymer. As for the dynamic analysis, it was observed that chitosan presents about $10 \%$ of weight loss that corresponds to the evaporation of physically adsorbed and strongly hydrogen bonded water to chitosan. ${ }^{45}$ The degradation of chitosan occurs between $245^{\circ} \mathrm{C}$ and $350^{\circ} \mathrm{C}$ which corresponds to the decomposition of polymer chains. ${ }^{45,46}$ Finally, a stage around $470{ }^{\circ} \mathrm{C}$ and $530{ }^{\circ} \mathrm{C}$ corresponding to residual decomposition reactions. ${ }^{46}$

\section{Differential scanning calorimetry (DSC)}

Figure 2 (b) shows the DSC curves obtained for the polymers synthesized with each polyol and with the minimum and maximum amounts of Ch addition.

By evaluating the DSC curves, the glass transition temperature of the PUs synthesized in this project was determined (complete data not shown). In the analysis in Figure 2 (b) it can be seen that polyols $\mathrm{CO}, \mathrm{P} 0$ y $\mathrm{P} 1$ without $\mathrm{Ch}$ have glass transition temperature of $-33.85^{\circ} \mathrm{C},-27.85^{\circ} \mathrm{C}$ and $-21.87^{\circ} \mathrm{C}$, respectively. These results tend to be lower when the maximum concentration of Ch ( $3 \%$ of Ch) is used, that is, $-37.86^{\circ} \mathrm{C},-31.87^{\circ} \mathrm{C}$ and $-23.86^{\circ} \mathrm{C}$ for polyols $\mathrm{CO}, \mathrm{P} 0$ and $\mathrm{P} 1$, respectively. The glass transition temperature results are similar to those reported for polyurethanes based on polyethylene glycol, poly (E-caprolactone-co-D, L-lactide) and diurethane diisocyanate (based on hexamethylene diisocyanate and butanediol), for which the 
Journal of material research, 2017, 32 (19): 3699-3711, doi:10.1557/jmr.2017.371

authors found values close to $-33^{\circ} \mathrm{C}$. The authors did not find exothermic peaks because the materials were amorphous. ${ }^{34}$

4. Water absorption and contact angle

The hydrophilic character of PUs was determined by calculating the absorption percentage, and the results are presented in Table III.

TABLE III. Water absorption of the PUs after 15 days.

\begin{tabular}{lc}
\hline Polyurethane & Water absorption (\%) \\
\hline CO-0\%Ch & $2.02 \pm 1.03$ \\
CO-1\%Ch & $2.17 \pm 1.51$ \\
CO-2\%Ch & $5.78 \pm 3.01$ \\
CO-3\%Ch & $3.94 \pm 1.57$ \\
\hline P0-0\%Ch & $2.46 \pm 0.43$ \\
P0-1\%Ch & $2.42 \pm 1.03$ \\
P0-2\%Ch & $1.10 \pm 0.76$ \\
P0-3\%Ch & $1.66 \pm 0.68$ \\
\hline P1-0\%Ch & $3.11 \pm 2.76$ \\
\hline P1-1\%Ch & $2.62 \pm 1.36$ \\
\hline P1-2\%Ch & $0.70 \pm 1.24$ \\
\hline
\end{tabular}

Notes: Water absorption is given as the mean $\pm \mathrm{SD}(\mathrm{n}=3)$. 
Journal of material research, 2017, 32 (19): 3699-3711, doi:10.1557/jmr.2017.371

The swelling study was performed for 15 days. The water absorption was evaluated twice, at 5 and 15 days. The analysis of the results did not present statistical differences between the evaluation times. Table III shows the results obtained for the absorption of water at 15 days. The P1 PUs presented lower water absorption than those obtained from CO and P0 when the concentration of Ch was 2-3\%. The increase in hydrogen bonds due to the increase in the functionality of the polyol by the transesterification with pentaerythritol ${ }^{47}$ forms a barrier to the diffusion of fluid into the material. ${ }^{48}$

An analysis of the concentration of Ch showed that PUs with CO had greater swelling than those that do not contain Ch. Increasing the amount of Ch allows for more functional groups available to interact with the medium, which is also polar. However, when increasing the polyol functionality, the generated effect is inverse, as observed for P1 PUs that presented a significant reduction of swelling with respect to the PUs without Ch. Internal interactions (hydrogen bonds) increased the barrier effect by preventing diffusion of the fluid. In addition, the filler function of Ch causes the chains to be reorganized, presenting a reduction of the volumetric defects or vacancies where the water can be deposited. ${ }^{49}$

Marques et al. ${ }^{6}$ evaluated a bioadhesive synthesized from lactic acid in which the water absorption was $10 \%$. The authors noted that moderate percentages of water absorption improve the hemostatic character of the materials. ${ }^{6}$ This is why the PUs synthesized in this study can be suggested as bioadhesives.

To evaluate the hydrophilic character of the polymer matrices the contact angle was determined and the results are presented in Figure 3. 
Journal of material research, 2017, 32 (19): 3699-3711, doi:10.1557/jmr.2017.371

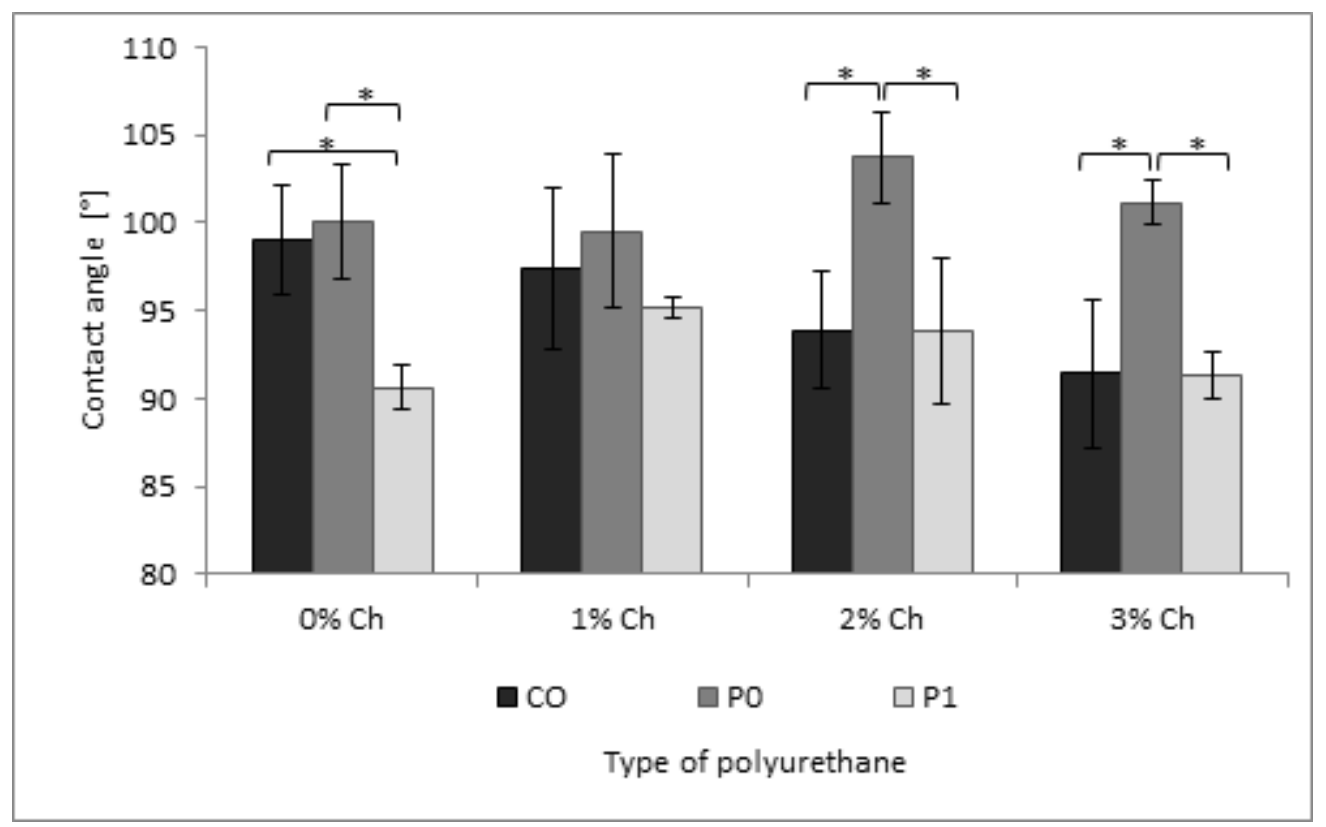

FIG. 3. Contact angle of the PUs.

Notes: The contact angle is given as the mean $\pm \mathrm{SD}(\mathrm{n}=10)$ * indicates statistical significance between polyol group type.

According to the statistical analysis in Figure 3, there are significant differences between the PUs synthesized with P1 and P0 and CO, with a reduction of the angle values. In evaluating the effect of Ch addition on contact angle values, it was observed that they did not present significant differences and therefore did not influence the hydrophilic character.

5. Scanning electron microscopy (SEM)

The morphology of the PUs as a function of the type of polyol and Ch addition used in synthesis is presented in Figure 4. 
Journal of material research, 2017, 32 (19): 3699-3711, doi:10.1557/jmr.2017.371
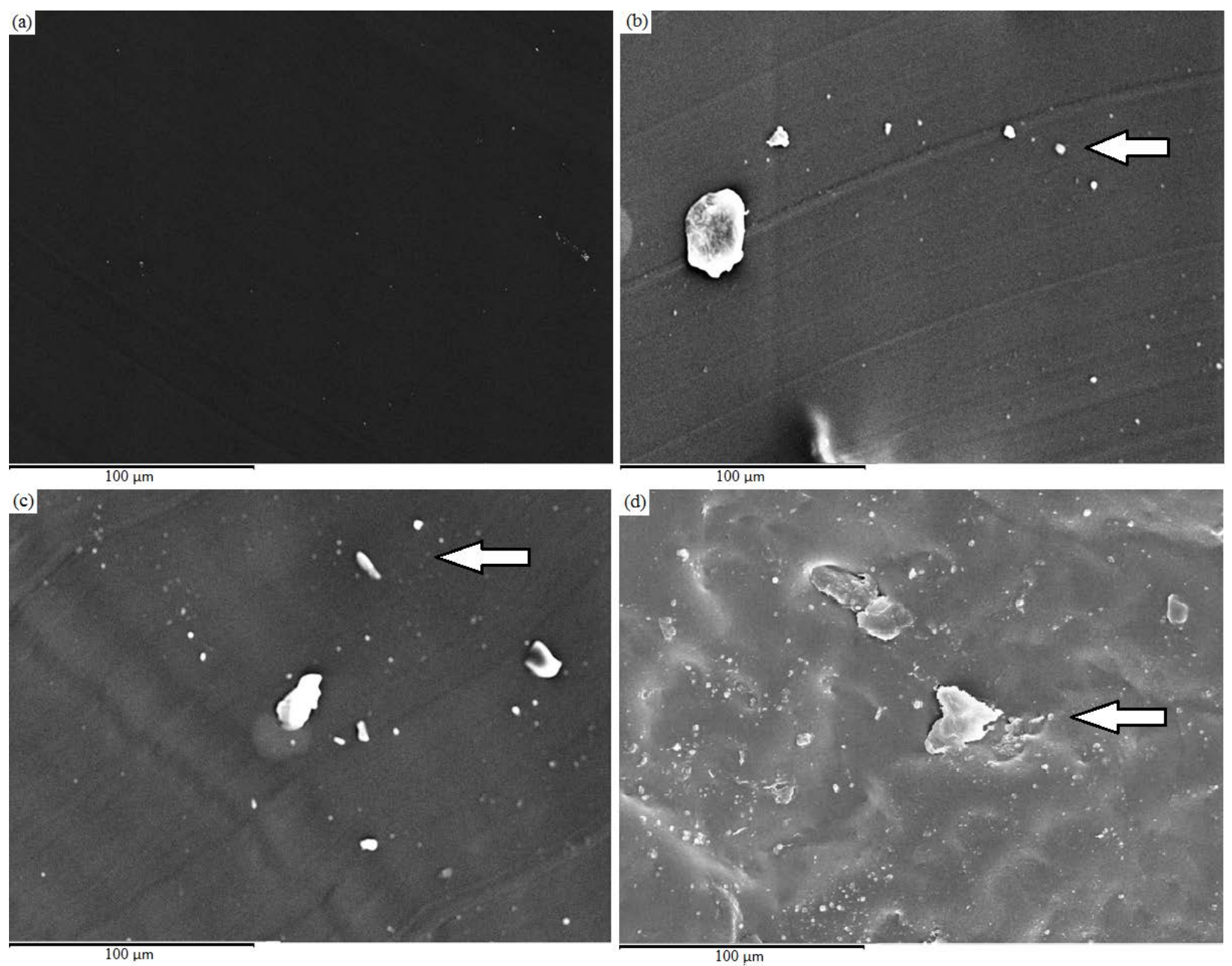

FIG. 4. SEM micrographs of the PUs at 500x. a) P1-0\%Ch, b) P1-1\%Ch, c) P1-2\%Ch, c) P1$3 \% \mathrm{Ch}$

In the micrographs presented in Figure 4, deposition of Ch granules on the surface of the material was observed. Additionally, roughness can be observed that is related to cell adhesion 49. It can also be inferred that by increasing of the amount of $\mathrm{Ch}$, an incompatibility between the matrix and Ch can occur that results in phase separation. Ch on the surface can improve cell viability for biocompatible properties. ${ }^{50}$ 
Journal of material research, 2017, 32 (19): 3699-3711, doi:10.1557/jmr.2017.371

\section{B. In vitro cytotoxicity of PUs}

Cellular viability was evaluated using the mouse fibroblast cell line L-929 on the PUs and the results are presented in Figure 5.

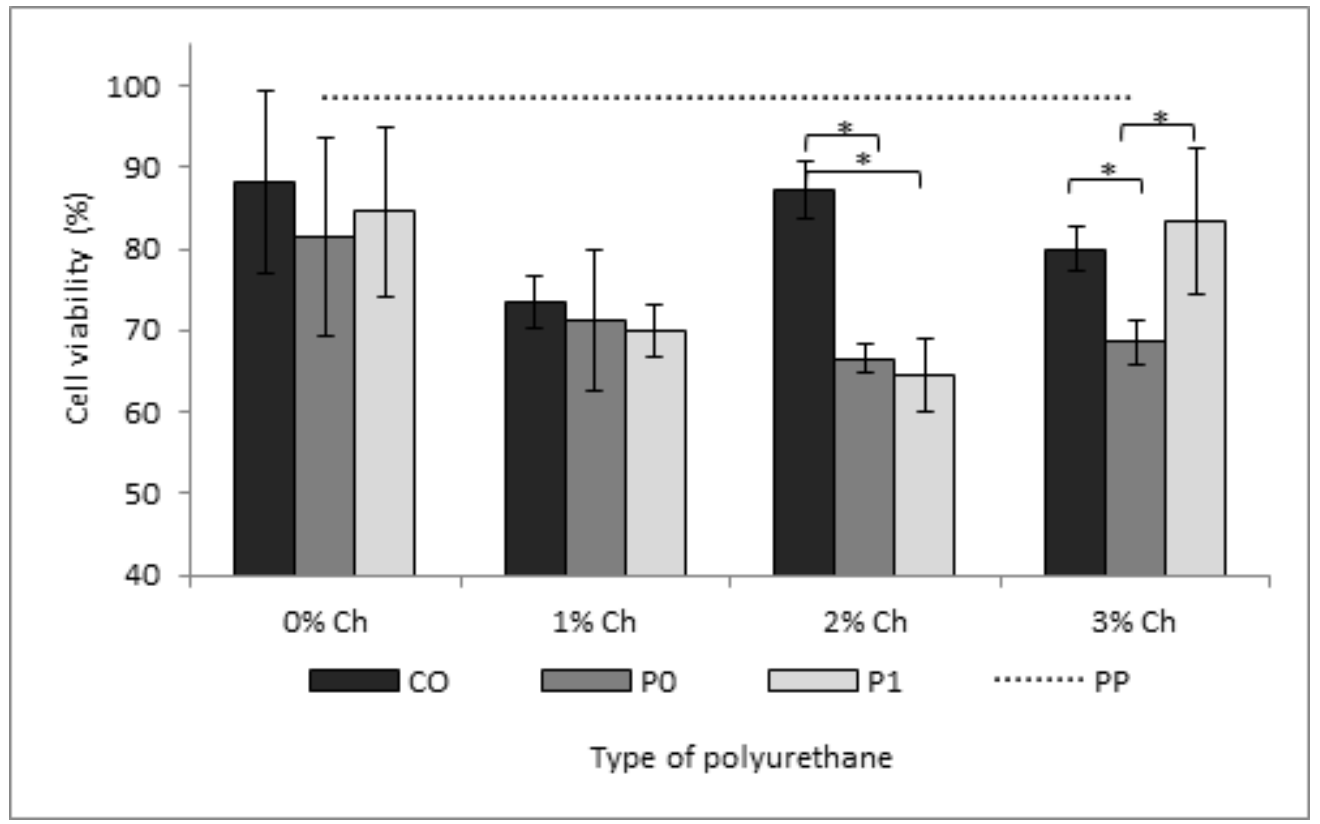

FIG. 5. Percentage of cellular viability of L-929 mouse fibroblasts at $24 \mathrm{~h}$.

Notes: The data are presented as the mean $\pm S D(n=3) . *$ indicates statistical significance between polyol group type.

Synthesized polymers generally have cell viability greater than $60 \%$, which is desirable when evaluating materials as candidates for biomedical applications. Statistical analysis of the polyol types used showed significant differences $(\mathrm{p}<0.05)$ between P0 and CO and P1 when the concentration of $\mathrm{Ch}$ was greater than $1 \%$. As a positive control a polypropylene biomaterial was used (98\% cell viability under the assay conditions). As a negative control doxorubicin at 50 ppm was used (37\% cell viability under the assay conditions). 
Journal of material research, 2017, 32 (19): 3699-3711, doi:10.1557/jmr.2017.371

With the evaluation about the effect of the Ch addition on cell viability, it can be inferred that the Ch addition did not apparently affect the evaluated cells.

Guo et al. ${ }^{4}$ used a strategy to increase the cohesive strength of the adhesives to design crosslinked polymers with mechanical and biocompatible resistance. The cellular viability of cross-linked bioadhesives was similar to a commercial biomaterial (poly(lactic-co-glycolic acid)). The results suggest that crosslinked bioadhesives can be used as bioadhesives. ${ }^{4}$

\section{Cell adhesion testing of PUs}

Mouse fibroblast cell line L-929 on the PUs were using to evaluated cellular adhesion test and the quantitative analysis are presented in Figure 6.

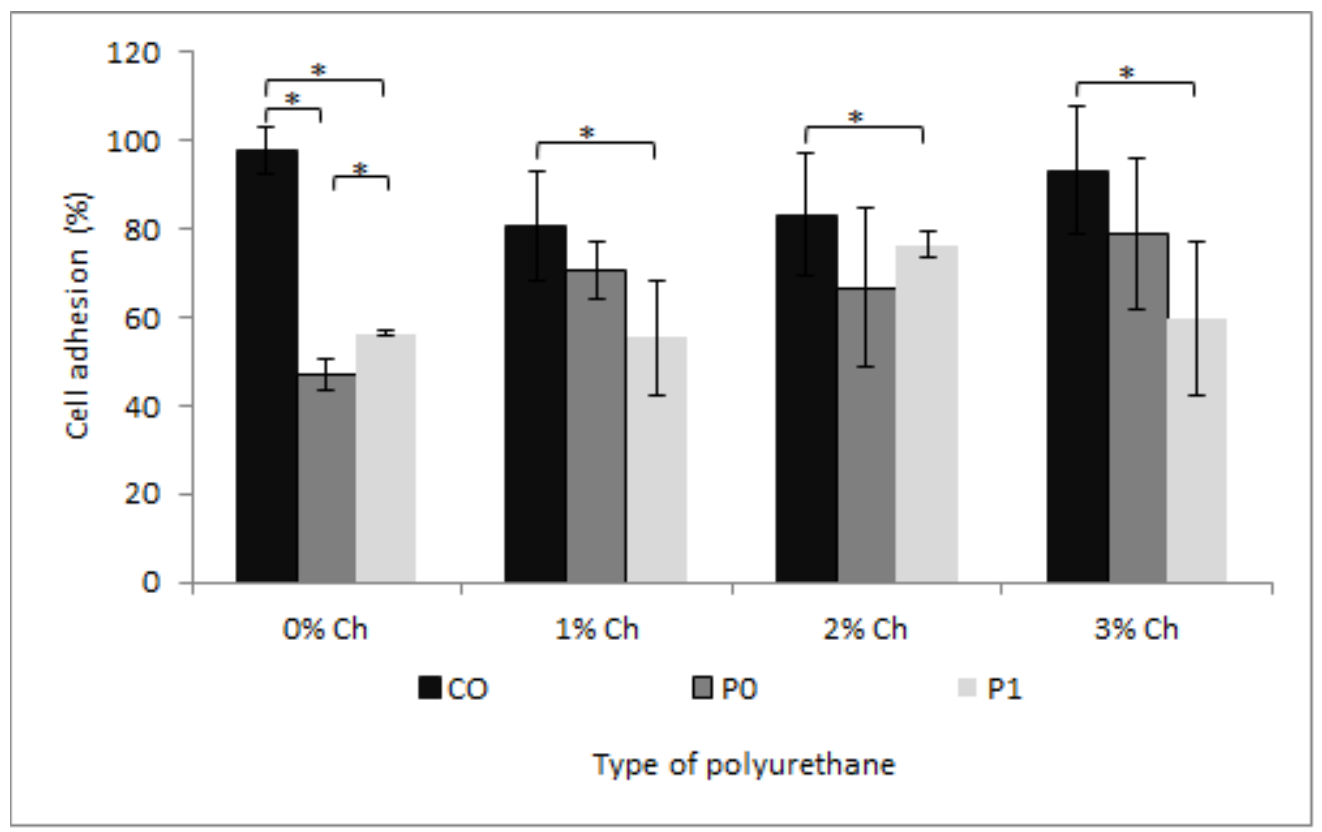

FIG. 6. Cellular adhesion of L-929 mouse fibroblasts at $48 \mathrm{~h}$ on PUs.

Notes: The data are presented as the mean $\pm \mathrm{SD}(\mathrm{n}=3) .{ }^{*}$ indicates statistical significance between polyol group type. 
Journal of material research, 2017, 32 (19): 3699-3711, doi:10.1557/jmr.2017.371

Statistical analysis of the polyol types used showed significant differences $(\mathrm{p}<0.05)$ between $\mathrm{CO}$ and P0 and P1. The effect of the Ch addition on cell adhesion was determined for each polyol, and significant differences in the results were observed for P0 and P1, indicating that the Ch addition did not apparently affect the evaluated cells adhesion. As a positive control a polystyrene standard tissue culture was used (104\% cell viability under the assay conditions at $48 \mathrm{~h}$ ). As a negative control doxorubicin at $50 \mathrm{ppm}$ was used (17 \% cell viability under the assay conditions at $48 \mathrm{~h})$.

Similar behavior was observed for adhesion assessments at 6 and $24 \mathrm{~h}$ (data not shown). All the PUs showed cell adhesion since $6 \mathrm{~h}$. The minimum and maximum values at $24 \mathrm{~h}$ were between $28 \%$ for $\mathrm{P} 0-0 \% \mathrm{Ch}$ and $78 \%$ for $\mathrm{CO}-2 \% \mathrm{Ch}$, respectively. These results show that the effect of the Ch addition tends to improve the adhesion of the L929 cells on the material. With the adhesion results, it can be inferred that the PUs synthesized with polyols derived from the castor oil and chitosan can be used as bioadhesives. Figure 7 shows cell morphology of L929 cells adhered to the polyurethane $\mathrm{P} 0-1 \% \mathrm{Ch}$ at $48 \mathrm{~h}$. 
Journal of material research, 2017, 32 (19): 3699-3711, doi:10.1557/jmr.2017.371

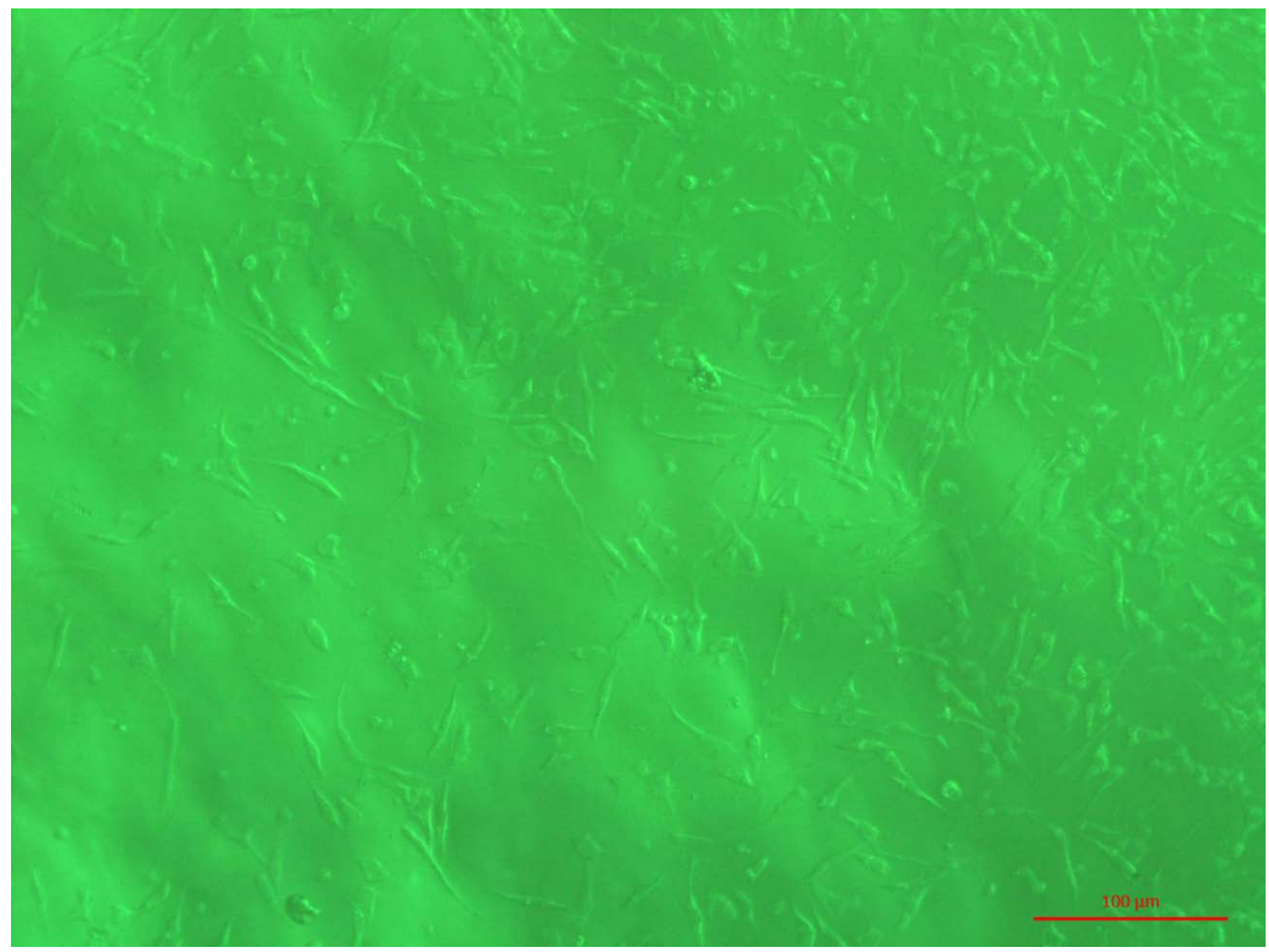

FIG. 7. Cell morphologies of L-929 mouse fibroblasts (10 X) on P0-1\%Ch at $48 \mathrm{~h}$.

Sordel et al. ${ }^{51}$ claim that cell adhesion on the surface of a material is an important factor to take into account when designing biomaterials. The adhesion of cells is important to fulfill a number of functions such as cell proliferation. ${ }^{51,52}$ Zhu et al. ${ }^{53}$ used human foreskin fibroblast cell line into collagen-chitosan hydrogel scaffolds and the authors suggest that the chitosan addition (20-30 \%) with collagen can significantly improve cell attachment and proliferation. The authors affirm that chitosan is usually used to endow scaffolds with sufficient mechanical strengths required for cell growth. ${ }^{53}$

\section{Antibacterial activity of PUs}

The antimicrobial activity of the polymeric materials synthesized was evaluated against 
Journal of material research, 2017, 32 (19): 3699-3711, doi:10.1557/jmr.2017.371

Gram-negative bacteria E. coli (ATCC® 2469), which is usually found in humans ${ }^{6}$ and the results are presented in Figure 8.

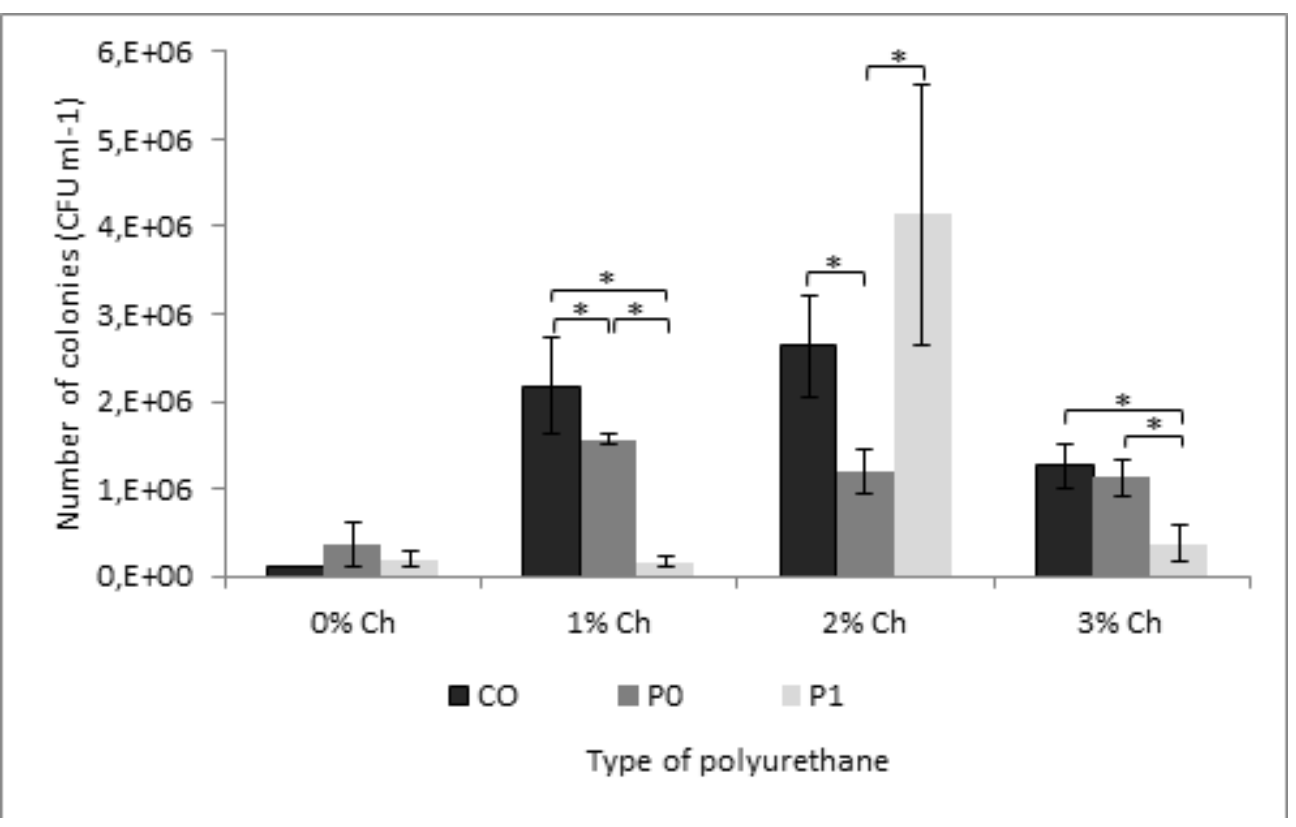

FIG. 8. Antibacterial activity of PUs against E. coli

Notes: The colony forming units per milliliter $\left(\mathrm{CFU} \mathrm{mL} \mathrm{m}^{-1}\right)$ are presented as the mean $\pm \mathrm{SD}(\mathrm{n}=3)$.

* indicates statistical significance between polyol group type.

The results in Figure 8 show that the PUs evaluated showed bacterial inhibition against $E$. coli, with percentages of inhibition between $60 \%$ and $90 \%$ compared to the control $(1,17 \mathrm{E}+07$ $\mathrm{CFU} \mathrm{mL} \mathrm{m}^{-1}$ ). When performing the analysis for the polyols, P1 presents significant differences with respect to $\mathrm{CO}$ and $\mathrm{P} 0$. The statistical analysis of the results of PUs synthesized with CO did not present significant differences for the concentration of $\mathrm{Ch}$, so an optimal concentration of $\mathrm{Ch}$ cannot be inferred. For P0 and P1, there were statistical differences related to the concentration of Ch. It was expected that increasing the Ch concentration would present bacterial inhibition, but Ch is apparently trapped in the polymer matrix, which prevents the release of $\mathrm{Ch}$ in $24 \mathrm{~h}$. 
Journal of material research, 2017, 32 (19): 3699-3711, doi:10.1557/jmr.2017.371

Additional to this, Liu et al. ${ }^{54}$ suggest that some factors affecting the antibacterial activity of chitosan like molecular weight and concentration. For these reason, is more effective used higher concentrations of chitosan (higher than 10,000 Da for example) for microorganism inhibition. ${ }^{54}$ In this research the chitosan used was low-molecular-weight and low concentration (3\%). Is possible that the results showed no significant differences for the molecular weight and concentration of chitosan used.

The polymers synthesized in this project generally have antibacterial activity against Gramnegative bacteria, and this property is ideal for polymers used as bioadhesives.

\section{CONCLUSIONS}

PUs were synthesized with polyols derived from castor oil, HDI and Ch. The polyols were chemically modified with pentaerythritol to increase the hydroxyl groups that generate crosslinking. An evaluation of the mechanical, adhesive, thermal and morphological properties, as well as the in vitro cytotoxicity, cellular adhesion and in vitro antimicrobial activity was performed. Chemical modification of the polyols increases the mechanical and adhesive properties due to an increase in the physical crosslinks of the polymers. The PUs were not toxic and revealed cellular adhesion for all polyols evaluated. The PUs evaluated showed bacterial inhibition against E. coli, presenting inhibition between $60 \%$ and $90 \%$ compared to the control. In general, the mechanical, adhesive, and biological properties suggest that the PUs synthetized in this research may be candidates for external biomedical tissue adhesives. 
Journal of material research, 2017, 32 (19): 3699-3711, doi:10.1557/jmr.2017.371

\section{ACKNOWLEDGMENTS}

The authors thank the Universidad de La Sabana for financing research project ING-176-2016 which is part of this research, Colciencias for the doctoral scholarship under grant 617-2 of 2014, and the Universitat Politècnica de València for assistance and advice with the equipment.

\section{DISCLOSURE STATEMENT}

No potential conflicts of interest were reported by the authors.

\section{FUNDING}

This work was supported by the Universidad de La Sabana under grant number ING-1762016 and by Colciencias under scholarship grant 617-2-2014. CIBER-BBN is an initiative funded by the VI National R\&D\&I Plan 2008-2011, Iniciativa Ingenio 2010, Consolider Program. CIBER Actions are financed by the Instituto de Salud Carlos III with assistance from the European Regional Development Fund. J.A.G.T. and A.V.L. acknowledge the support of the Spanish Ministry of Economy and Competitiveness (MINECO) through project DPI2015-65401C3-2-R (including FEDER financial support).

\section{REFERENCES}

1. B. Ates, S. Koytepe, M. G. Karaaslan, S. Balcioglu, S. Gulgen: Biodegradable non-aromatic adhesive polyurethanes based on disaccharides for medical applications. Int. J. Adhes. Adhes. 49, 90 (2014).

2. P. J. M. Bouten, M. Zonjee, J. Bender, S. T. K. Yauw, H. Van Goor, J. C. M. Van Hest, R. Hoogenboom: The chemistry of tissue adhesive materials. Prog. Polym. Sci. 39, 1375 (2014). 3. A. K. Patel: Chitosan: emergence as potent candidate for green adhesive market. Biochem. 
Journal of material research, 2017, 32 (19): 3699-3711, doi:10.1557/jmr.2017.371

Eng. J. 102, 74 (2015).

4. J. Guo, G. B. Kim, D. Shan, J. P. Kim, J. Hu, W. Wang, F. G. Hamad, G. Qian, E. B. Rizk, J. Yang: Click chemistry improved wet adhesion strength of mussel-inspired citrate-based antimicrobial bioadhesives. Biomaterials. 112, 275 (2017).

5. S. Khanlari, J. Tang, K. M. Kirkwood,M. Dubé: Synthesis and properties of a poly(sodium acrylate) bioadhesive nanocomposite. Int. J. Polym. Mater. Polym. Biomater. 65, 881 (2016).

6. D. S. Marques, J. M. C. Santos, P. Ferreira, T. R. Correia, I. J. Correia, M. H. Gil, C. M. S. G. Baptista: Photocurable bioadhesive based on lactic acid. Mater. Sci. Eng. C, 58, 601 (2016).

7. O. Jeon, J. E. Samorezov, E. Alsberg: Single and dual crosslinked oxidized methacrylated alginate/PEG hydrogels for bioadhesive applications. Acta Biomater. 10, 47 (2014).

8. J. C. Wheat, J. S. Wolf: Advances in bioadhesives, tissue sealants, and hemostatic agents. Urol. Clin. NA, 36, 265 (2009).

9. M. Mehdizadeh, H. Weng, D. Gyawali, L. Tang, J. Yang: Biomaterials Injectable citrate-based mussel-inspired tissue bioadhesives with high wet strength for sutureless wound closure. Biomaterials, 33, 7972 (2012).

10. J. Guo, W. Wang, J. Hu, D. Xie, E. Gerhard, M. Nisic, D. Shan, G. Qian, S. Zheng, J. Yang: Biomaterials Synthesis and characterization of anti-bacterial and anti-fungal citrate-based mussel-inspired bioadhesives. Biomaterials, 85, 204 (2016).

11. K. M. Seeni Meera, R. Murali Sankar, J. Paul, S. N. Jaisankar, A. B. Mandal: The influence of applied silica nanoparticles on a bio-renewable castor oil based polyurethane nanocomposite and its physicochemical properties. Phys. Chem. Chem. Phys. PCCP, 16, 9276 (2014).

12. M. Szycher, M. In Szycher’s Handbook of Polyurethanes; (CRC Press Inc: Boca Ratón, 2012); cap. 22. 
Journal of material research, 2017, 32 (19): 3699-3711, doi:10.1557/jmr.2017.371

13. P. Alves, P. Ferreira, M. H. Gil: In Polyurethane: Properties, Structure and Applications;

Cavaco, L. I.,; Melo, J. A., orgs.; (Nova Science Publishers: New York, 2012); cap. 1.

14. A. Usman, K. M. Zia, M. Zuber, S. Tabasum, S. Rehman, F. Zia: Chitin and chitosan based polyurethanes: a review of recent advances and prospective biomedical applications. Int. J. Biol. Macromol. 86, 630 (2016).

15. G. Kaur, M. Mahajan, P. Bassi: Derivatized Polysaccharides: preparation, characterization, and application as bioadhesive polymer for drug delivery. Int. J. Polym. Mater. 62, 475 (2013). 16. T. S. Anirudhan, S. S. Nair, A. S. Nair: Fabrication of a bioadhesive transdermal device from chitosan and hyaluronic acid for the controlled release of lidocaine. Carbohydr. Polym. 152, 687 (2016).

17. Y. G. Liu, C. R. Zhou, Y. A. Sun: A biomimetic strategy for controllable degradation of chitosan scaffolds. J. Mater. Res. 27, 1859 (2012).

18. L. Maisonneuve, G. Chollet, E. Grau, H. Cramail: Vegetable oils: a source of polyols for polyurethane materials. Oilseeds fats Crop. Lipids, 23, D508 (2016).

19. P. Narute, A. Palanisamy: Study of the performance of polyurethane coatings derived from cottonseed oil polyol. J. Coatings Technol. Res. 13, 171 (2016).

20. Y. Uscátegui, F. Arévalo, L. Díaz, M. Cobo, M. Valero: Microbial degradation, cytotoxicity and antibacterial activity of polyurethanes based on modified castor oil and polycaprolactone. $J$. Biomater. Sci. Polym. Ed. 27, 1860 (2016).

21. A. Shaik, R. Narayan, K. V. S. N. Raju: Synthesis and properties of siloxane-crosslinked polyurethane-urea/silica hybrid films from castor oil. J. Coatings Technol. Res. 11, 397 (2014). 22. M. F. Valero, A. Gonzalez: Polyurethane adhesive system from castor oil modified by a transesterification reaction. J. Elastomers Plast., 44, 433 (2012). 
Journal of material research, 2017, 32 (19): 3699-3711, doi:10.1557/jmr.2017.371

23. M. F. Valero, Y. Ortegón: Polyurethane elastomers-based modified castor oil and poly(ecaprolactone) for surface-coating applications: synthesis, characterization, and in vitro degradation. J. Elastomers Plast. 47, 360 (2015).

24. M. F. Valero, L. E. Díaz: Poliuretanos obtenidos a partir de aceite de higuerilla modificado y poli-isocianatos de lisina: síntesis, propiedades mecánicas y térmicas y degradación in vitro. Quim. Nova, 37, 1441 (2014).

25. F. Arevalo, Y. L. Uscategui, L. E. Diaz, M. Cobo, M. F. Valero: Effect of the incorporation of chitosan on the physico-chemical, mechanical properties and biological activity on a mixture of polycaprolactone and polyurethanes obtained from castor oil. J. Biomater. Appl. 31, 708 (2016).

26. S. M. Cakić, I. S. Ristić, M. M. Cincović, N. C. Nikolić, L. Nikolić, M. J. Cvetinov: Synthesis and properties biobased waterborne polyurethanes from glycolysis product of PET waste and poly (caprolactone) diol. Prog. Org. Coatings 105, 111 (2017).

27. Á. Conejero-García, H. R. Gimeno, Y. M. Sáez, G. Vilariño-Feltrer, I. Ortuño-Lizarán, A. Vallés-Lluch: Correlating synthesis parameters with physicochemical properties of poly(glycerol sebacate). Eur. Polym. J. 87, 406 (2017).

28. K. M. Zia, M. Zuber, M. J. Saif, M. Jawaid, K. Mahmood, M. Shahid, M. N. Anjum, M. N. Ahmad: Chitin based polyurethanes using hydroxyl terminated polybutadiene, part III: surface characteristics. Int. J. Biol. Macromol. 62, 670 (2013).

29. J. Skrobot, L. Zair, M. Ostrowski, M. Fray: El Biomaterials new injectable elastomeric biomaterials for hernia repair and their biocompatibility. Biomaterials, 75, 182 (2016). 30. T. Riaz, A. Ahmad, S. Saleemi, M. Adrees, F. Jamshed, A. Moqeet, T. Jamil: Synthesis and characterization of polyurethane-cellulose acetate blend membrane for chromium (VI) removal. 
Journal of material research, 2017, 32 (19): 3699-3711, doi:10.1557/jmr.2017.371

Carbohydr. Polym. 153, 582 (2016).

31. R. Pignatello, G. Impallomeni, V. Pistarà, S. Cupri, A. C. E. Graziano, V. Cardile, A. Ballistreri: New amphiphilic derivatives of poly(ethylene glycol) (PEG) as surface modifiers of colloidal drug carriers. III. Lipoamino acid conjugates with carboxy- and amino-PEG(5000) polymers. Mater. Sci. Eng. C, 46, 470 (2015).

32. M. Arnal-Pastor, S. Comin-Cebrian, C. Martinez-Ramos, M. Monleon Pradas, A. VallesLluch: Hydrophilic surface modification of acrylate-based biomaterials. J. Biomater. Appl. 30, 1429 (2016).

33. H. Bakhshi, H. Yeganeh, S. Mehdipour-Ataei, M. A. Shokrgozar, A. Yari, S. N. SaeediEslami: Synthesis and characterization of antibacterial polyurethane coatings from quaternary ammonium salts functionalized soybean oil based polyols. Mater. Sci. Eng. C 33, 153 (2013). 34. Z. Hou, H. Zhang, W. Qu, Z. Xu, Z. Han: Biomedical segmented polyurethanes based on polyethylene glycol, poly( $\varepsilon$-caprolactone-co- D,L -lactide), and diurethane diisocyanates with uniform hard segment: synthesis and properties. Int. J. Polym. Mater. Polym. Biomater. 65, 947 (2016).

35. P. Gentile, D. Bellucci, A. Sola, C. Mattu, V. Cannillo, G. Ciardelli: Composite scaffolds for controlled drug release: role of the polyurethane nanoparticles on the physical properties and cell behaviour. J. Mech. Behav. Biomed. Mater. 44, 53 (2015).

36. A. Pitchaimani, T. Duong, T. Nguyen, M. Koirala: Impact of cell adhesion and migration on nanoparticle uptake and cellular toxicity. Toxicol. Vitr. 43, 29 (2017).

37. F. Kara, E. A. Aksoy, Z. Yuksekdag, N. Hasirci, S. Aksoy: Synthesis and surface modification of polyurethanes with chitosan for antibacterial properties. Carbohydr. Polym. 112, 39 (2014). 
Journal of material research, 2017, 32 (19): 3699-3711, doi:10.1557/jmr.2017.371

38. M. F. Valero, J. E. Pulido, Á. Ramírez, Z. Cheng: Sintesis de poliuretanos a partir de polioles obtenidos a partir del aceite de higuerilla modificado por transesterificación con pentaeritritol. Quim. Nova, 31, 2076 (2008).

39. S. M. Cakić, I. S. Ristić, M. M. Cincović, D. T. Stojiljković, C. J. János, M. J. Cvetinov, J. V. Stamenković: Glycolyzed poly (ethylene terephthalate) waste and castor oil-based polyols for waterborne polyurethane adhesives containing hexamethoxymethyl melamine. Prog. Org. Coatings, 78, 357 (2015).

40. M. Kathalewar, A. Sabnis, D. D’Mello: Isocyanate free polyurethanes from new CNSL based bis-cyclic carbonate and its application in coatings. Eur. Polym. J. J. 57, 99 (2014).

41. M. M. Aung, Z. Yaakob, S. Kamarudin, L. C. Abdullah: Synthesis and characterization of Jatropha (Jatropha curcas L.) oil-based polyurethane wood adhesive. Ind. Crops Prod. 60, 177 (2014).

42. P. Ferreira, R. Pereira, J. F. J. Coelho, A. F. M. Silva, M. H. Gil: Modification of the biopolymer castor oil with free isocyanate groups to be applied as bioadhesive. Int. J. Biol. Macromol. 40, 144 (2007).

43. H. Bakhshi, H. Yeganeh, A. Yari, S. K. Nezhad: Castor oil-based polyurethane coatings containing benzyl triethanol ammonium chloride: synthesis, characterization, and biological properties. J. Mater. Sci. 49, 5365 (2014).

44. M. A. Corcuera, L. Rueda, B. Fernandez d’Arlas, A. Arbelaiz, C. Marieta, I. Mondragon, A. Eceiza: Microstructure and properties of polyurethanes derived from castor oil. Polym. Degrad. Stab. 95, 2175 (2010).

45. H. Moussout, H. Ahlafi, M. Aazza, M. Bourakhouadar: Kinetics and mechanism of the thermal degradation of biopolymers chitin and chitosan using thermogravimetric analysis. 
Journal of material research, 2017, 32 (19): 3699-3711, doi:10.1557/jmr.2017.371

Polym. Degrad. Stab., 130, 1 (2016).

46. M. A. Gámiz-González, D. M. Correia, S. Lanceros-Mendez, V. Sencadas, J. L. Gómez Ribelles, A. Vidaurre: Kinetic study of thermal degradation of chitosan as a function of deacetylation degree. Carbohydr. Polym., 167, 52 (2017).

47. M. F. Valero, J. E. Pulido, Á. Ramírez, Z. Cheng, Z. Determinación de la densidad de entrecruzamiento de poliuretanos obtenidos a partir de aceite de ricino modificado por transesterificación. Polímeros, 19, 14 (2009).

48. M. F. Valero, L. E. Díaz: Poliuretanos obtenidos a partir de aceite de higuerilla modificado y poli-isocianatos de lisina: síntesis, propiedades mecánicas y térmicas y degradación in vitro. Quim. Nova, 37, 1441 (2014).

49. J. S. Temenoff, A. G. Mikos: Biomaterials (Pearson/Prentice Hall: Upper Saddle River, N.J., 2008).

50. D. Depan, P. K. C. V. Surya, B. Girase, R. D. K. Misra: Organic/inorganic hybrid network structure nanocomposite scaffolds based on grafted chitosan for tissue engineering. Acta Biomater. 7, 2163 (2011).

51. T. Sordel, F. Kermarec-Marcel, S. Garnier-Raveaud, N. Glade, F. Sauter-Starace, C. Pudda, M. Borella, M. Plissonnier, F. Chatelain, F. Bruckert, N. Picollet-D’hahan: Influence of glass and polymer coatings on CHO cell morphology and adhesion. Biomaterials 28, 1572 (2007).

52. V. Pehlivanova, V. Krasteva, B. Seifert, K. Lützow, I. Tsoneva, T. Becker, K. Richau, A. Lendlein, R. Tzoneva: The role of alternating current electric field for cell adhesion on 2D and 3D biomimetic scaffolds based on polymer materials and adhesive proteins. J. Mater. Res. 28, 2180 (2013).

53. Y. Zhu, Z. Dong, U. C. Wejinya, S. Jin, K. Ye: Determination of mechanical properties of 
Journal of material research, 2017, 32 (19): 3699-3711, doi:10.1557/jmr.2017.371

soft tissue scaffolds by atomic force microscopy nanoindentation. J. Biomech. 44, 2356 (2011).

54. N. Liu, X. G. Chen, H. J. Park, C. G. Liu, C. S. Liu, X. H. Meng, L. J. Yu: Effect of MW and concentration of chitosan on antibacterial activity of Escherichia coli. Carbohydr. Polym. 64, 60 (2006). 